LITERATURA Y CINE EN LA ENCRUCIJADA DE LA GLOBALIZACIÓN Y LOS MEDIOS DE COMUNICACIÓN Grand Junction, Colorado

28-29 OCTUBRE 2011

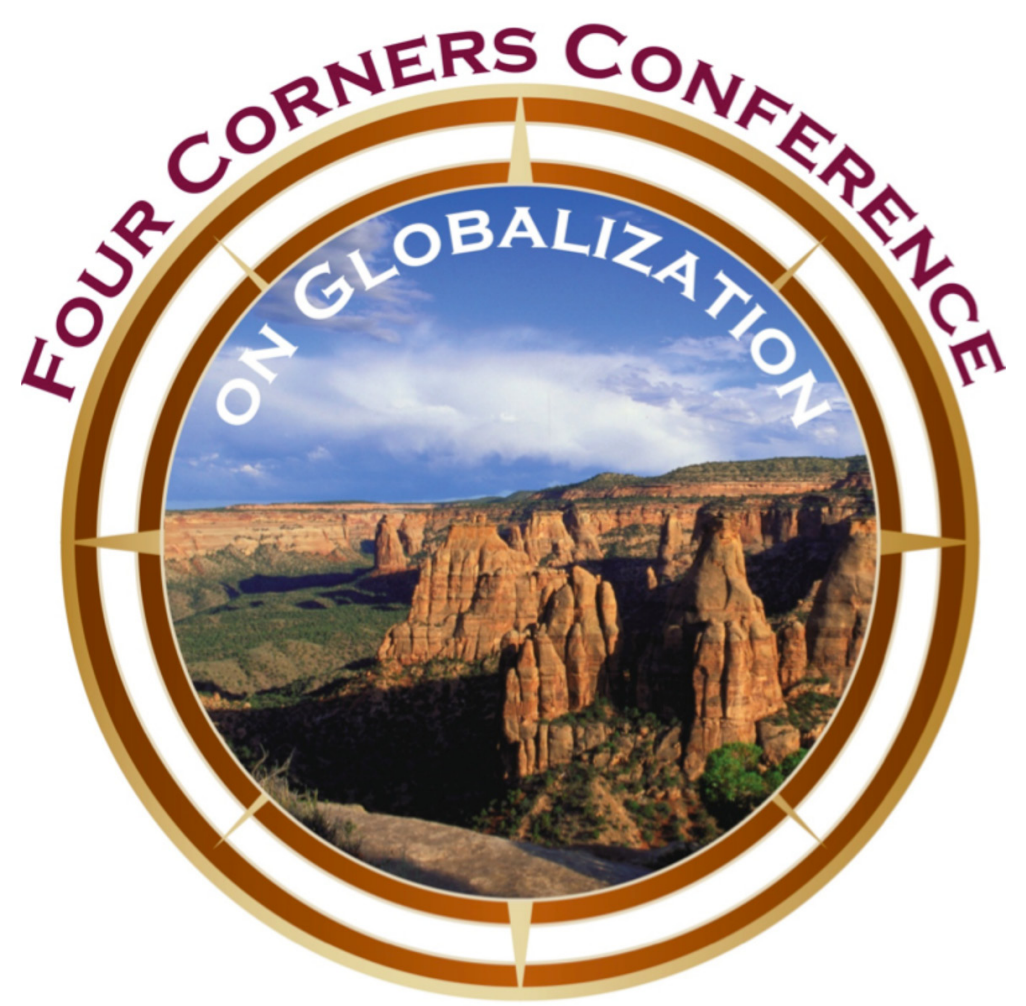





\title{
LA ZONA, UNA CIUDAD DE MÉXICO GLOBALIZADA Y COLAPSADA POR LA VIOLENCIA
}

\author{
Demetrio Anzaldo-González
}

\begin{abstract}
RESUMEN
La injusta realidad de lo que se vive en las ciudades y espacios poblacionales tercermundistas globalizados muestra ya claras señales de una descomposición social que sigue deteriorándose ante la falta de oportunidades y de educación para las actuales y futuras generaciones de ciudadanos. La violencia, pobreza, corrupción, desesperación, segregación y muerte son alarmantes. Dentro de este planteamiento crítico, la película, La zona, retoma distintas mitificaciones, memorias e imágenes al interior de una ciudad de México colapsada. El tema central en esta historia fílmica es la violencia y su impacto brutal en la sociedad. La zona es parte del desastre que se avizora para los habitantes de las megalópolis que, como la ciudad de México, inmolan a sus jóvenes.
\end{abstract}

Palabras clave: cine, Ciudad de México, violencia, globalización, segregación, crisis social.

\begin{abstract}
The disparities of social life as seen in the globalized Third world's cities and urban spaces, have shown obvious symptoms of a terrible social decomposition that continues to worsen due to the lack of educational opportunities for their present and future citizenry. Violence, poverty, corruption, desperation, segregation and death are alarming factors affecting societies. Under this critical framework, the film, La zona, portrays different myths, memories and images lived in a collapsed Mexico City. The movie's main theme is violence and its terrible consequences in Mexican society. La zona is part of the imminent apocalyptical era deserved for the human populations living in megalopolis such as Mexico City, enormous cities that tend to sacrifice the population of their youth. Key words: cinema, Mexico City, violence, globalization, segregation, social crisis.
\end{abstract}

Recordar es, cada vez más, no tanto recordar una historia sino ser capaz de evocar una imagen.

(Sontag 2003: 104)

[...] islas, fragmentos y fortificaciones conforman las ciudades de hoy.

(Makowski 2007: 10)

Dr. Demetrio Anzaldo-González. Associate Teaching Professor of Spanish. Department of Romance Languages and Literatures University of Missouri

Correo electrónico: anzaldod@missouri.edu

Recepción: 01- 02- 2012

Aceptación: 06- 03- 2012 
Al contrario de lo esperado por los gobiernos europeos, asiáticos y estadounidense líderes en el acontecer mundial, no sólo se ha aumentado la brecha separatista entre todos los países del mundo como consecuencia de un sistema económico-político sustentando movimientos monopólicos nacionalistas, racistas y belicistas, sino que también se ha acrecentado la apatía, el desencanto y la renunciación entre la población misma. Ante esta situación mundial, hecha ya parte de lo cotidiano, las guerras y la violencia se han incrementado a la par de los sentimientos de miedo, terror, xenofobia, desamparo y desilusión ante el presente caos socio-económico globalizado. En la primera década del siglo XXI, las propuestas hegemónicas por consolidar un mundo globalizado en el que los ciudadanos y países del mundo entero se unieran para vivir en armonía han fallado.

El acercamiento globalizador propuesto se ha convertido en un problema constante, tanto para los gobernantes como para los gobernados; es además un dilema existencial que va en aumento y que ha cobrado relevancia en los grandes centros urbanos o megalópolis debido a esa alta concentración poblacional, cultural y comercial generando tensiones y conflictos. En su ensayo, "Capitales de la cultura y ciudades globales", García Canclini puntualiza que

\footnotetext{
En las megalópolis de Asia y América Latina las crisis económicas y financieras y el adelgazamiento de los Estados han reducido la posibilidad de mejorar los servicios y la seguridad, movilizar nuevos recursos económicos y culturales con vistas a renovar y expandir su vida urbana y su proyección interna. (2010: 168)
}

La injusta realidad o realidades de lo que se vive en las ciudades y espacios poblacionales tercermundistas globalizados muestra ya claras señales de una descomposición social que sigue deteriorándose -al parecer de manera irreversible- ante la falta de oportunidades y de educación para las actuales y futuras generaciones de ciudadanos. La violencia, pobreza, corrupción, desesperación, segregación y muerte son alarmantes y son síntomas de un peligro mucho mayor que podría suscitarse si estas problemáticas humanas llegaran a estar fuera de control.

Ante ese inminente cataclismo mundial que se avecina y se percibe en la escena del mundo, el cine no podría dejar de hacerse presente. El auge de lo visual por sobre lo escrito, del movimiento por sobre la inmovilidad y del poder de masas del lenguaje cinematográfico sobre cualquier otro medio comunicativo, lo han puesto a la cabeza y al servicio de las ciencias y de las bellas artes. La avalancha de éxitos de todo tipo que las imágenes cinematográficas han generado desde su nacimiento a finales del siglo XIX hasta el momento presente sigue siendo inobjetable. Actualmente, la comunicación que se logra con el cinematógrafo ofrece múltiples oportunidades para dialogar entre mundos culturales y geografías humanas desconocidas y equidistantes, puestos en contacto mediante luces, sombras, sonidos, silencios, tiempos, temporalidades, lugares, lenguajes, mitos, memorias e imágenes dentro de la gran pantalla.

Esta ventana comunicativa, interactuando con la humana realidad del espectador, pone enfrente del público el acontecer local y global de forma tal que recupera memorias e imágenes del acontecer actual y de lo ya sucedido. No hay mejor memoria humana que la que el cine -en conjunción con las demás ciencias y artes- registra y proyecta. La información y comunicación dada desde la pantalla conlleva a razonamientos e interpretaciones, aproximaciones y perspectivas producto de un impacto personal y social tanto entre los realizadores como entre los espectadores de las otras realidades sugeridas por los extraordinarios juegos de luces y sombras en movimiento.

El cine como un arte colectivo de rápido acceso para la mayor parte de la población dentro de un mundo globalizado que, paradójicamente se encuentra dividido en regiones, 
tiene un gran alcance informativo-comunicacional. Por esto mismo, este mantiene una importancia primordial en los distintos círculos poblacionales y socioculturales de nuestra realidad presente; puesto que toda la información que vemos en la pantalla nos llega directa y voluntariamente del exterior a nuestro fuero interno para después ser asimilada/procesada por nuestro cerebro (Pasantes 1999: 178) mediante sentidos e impulsos eléctricos del infinito procesamiento de todo nuestro sistema nervioso. Los mundos reales e irreales, imágenes y espacios llenos de luces y sombras, encuentran en el cine un punto mediático altamente aleccionador. Esta particularidad tan extraordinaria que tiene el cine para presentar/proyectar ese otro acontecer local y global de diferentes maneras recupera memorias e imágenes del pasado y del presente obligándonos a repensar lo antes visto, De manera simultánea, el cine potencializa un proceso mental creativo/concientizado que nos acerca más al conocimiento y comprensión de las realidades de lo que sucede en nuestro entorno y, por extensión, en nuestro planeta. Con lo anterior, se constata aquello de que en "el cine visualmente también se representan (o se hacen visibles) "los mundos imaginarios", mundos que han ayudado a construir un imaginario visual común en todo el mundo" (Bittarello 2008: 6).

La nueva información y visión dada/proporcionada por el cine conlleva a formular interpretaciones y aproximaciones cuyos objetivos son los de lograr un impacto social tanto en los realizadores como entre los espectadores de estas otras realidades convertidas en luces y sombras. Es decir, todo se hace o se deshace mediante el hábil movimiento de las imágenes suscitadas y creadas por y para la realidad e imaginación humanas en el espacio virtual e ideado en el mundo del cine. El arte cinematográfico continúa siendo una de las actividades humanas por las que se logra acceder y comunicar diversos mensajes a las múltiples subjetividades que críticamente elaboran resemantizaciones de los parámetros culturales establecidos; porque,

\footnotetext{
La historia de la globalización apenas comienza. Su generalización de la interactividad está entorpecida no sólo por el "retraso" de las culturas poco integradas sino por las nuevas fronteras y la segmentación de circuitos y públicos inventadas por quienes afirman colocar al mundo en estado de telepresencia. Pese a la retórica unificadora, las diferencias históricas y locales persisten, ante todo, porque los poderes globalizadores son insuficientes para abarcar a todos y también porque su modo de reproducirse y expandirse necesita que el centro no esté en todas partes, que haya diferencias entre la circulación mundial de las mercancías y la distribución desigual de la capacidad política de usarlas. (García Canclini 2010: 201)
}

De este modo, la historia del cine hace historia por el esfuerzo de sus críticos y de las propuestas/desafíos que presentan los directores al llevar a la pantalla los hechos históricos del diario acontecer que van confrontando, edificando y destruyendo las sociedades humanas a lo largo de su existencia. Dentro de la memoria representada en la pantalla cinematográfica, conviene recordar las palabras y pensamientos de Walter Benjamin (1969), quien afirmaba:

El cine es una forma artística que va a la par de la creciente amenaza contra la vida que acecha al hombre moderno. La necesidad humana por enfrentarse directamente a los efectos traumatizantes de la existencia es una manera de ajustarse a los amenazantes peligros que acechan. (Benjamin 1969: 250)

En el pensamiento de Walter Benjamin, bulle de manera incesante esa relevancia que la construcción y desarrollo cultural de la ciudad y del cine mantiene con el devenir de la historia misma. Hay en su accionar filosófico una visión portentosa de lo que el cine alcanzaría a posteriori y, asimismo, hay un esclarecimiento de la estrecha relación que el cine mantiene para con la ciudad en sus variadas reapropiaciones y representaciones espaciales/especiales del cambiante mundo urbano/citadino. En sus abundantes notas y escritos sobre la ciudad, se revelarán también algunas otras de sus apreciaciones acerca del arte y, en especial, del arte cinematográfico. 
Al enfocarse en esta relación: cine y ciudad, Benjamin lleva a cabo una interesante comparación y recuento histórico donde las diferentes formas, con las que la arquitectura ha dotado a la ciudad de los hombres para garantizarles refugio, son vistas/analizadas críticamente. Al repasar los distintos alojamientos manufacturados y creados por este arte tan antiguo que acompaña a los seres humanos, él enfatiza ese aspecto social y colectivo inherente al arte arquitectónico. Lo que lo conlleva a establecer que,

\footnotetext{
La historia de la Arquitectura es más antigua que cualquier otro arte y (convalida) su reclamo a ser una fuerza viviente que tiene significancia en todo intento por comprender las relaciones de las masas para con el arte. [El mismo Walter Benjamin agrega que] las edificaciones son consignadas de una doble manera: por el uso y por la percepción mejor dicho por el contacto y por la vista. (Benjamin 169: 240)
}

A lo largo de su ulterior desarrollo tecnológico, social y multicultural, el arte cinematográfico es un arte de masas, al igual que la arquitectura, y nos llevan no sólo a visualizar lo asentado por el avezado crítico alemán, sino a confirmar la validez de sus ideas al estudiar al cine mexicano actual; en tanto que en este último los planos materiales se funden y confunden con los sensoriales y con aquellos otros emanados del subconsciente del espectador. Los mundos exteriores e interiores proyectados y procesados en la pantalla logran provocar la exaltación de mitos, memorias y pensamientos humanos. De hecho, es mediante las imágenes logradas por intermedio de la lente de una cámara cinematográfica que los sentidos y pensamientos humanos son accionados y confrontados por esa experiencia colectiva y simultánea que se vive por medio del cine. Son las creaciones artísticas con las que se describen, dinámica y proteicamente, las formas geométricas, espaciales, temporales y tangenciales vistas de manera especular/espectacular por un mundo confeccionado/imaginado en dos dimensiones. El arte cinematográfico acerca más todavía al hacer, al sentir, al pensar y repensar el quehacer/deshacer cotidianos que se gestan dentro de todas y cada una de las realidades humanas hacinadas en los múltiples espacios que toda ciudad crea, modifica o destruye. De cierta manera nos enfrentamos a un proceso cuestionador, a nuestra subjetividad en consonancia y con el influjo de las pasada memorias y mitos de la realidad tridimensional proyectados en la pantalla.

Dentro de este planteamiento crítico, la película, La zona (2007), de Rodrigo Plá, retoma distintas realidades, mitificaciones, memorias e imágenes que se viven cotidianamente en una sociedad segregada por "la desigualdad y la injusticia en la convivencia" (Langagne 2004-2005: 46). El tema central en esta historia fílmica es la violencia y su impacto en una sociedad determinada. Al interior de este filme, se presenta de manera silenciosa y espectacular una zona residencial homogénea, suntuosa, perfecta vista como un sitio idílico e inexpugnable. De manera intencional esta zona privilegiada se muestra con casas compactas llenas de luz y rodeadas de jardines y fuentes con pequeñas bardas limítrofes que se repiten alrededor de cada unidad habitacional en la que "todas las casas son iguales". La belleza del lugar privado y extremadamente protegido se transforma en un escenario donde deviene la extrema crueldad de sus habitantes. Precisamente, esa zona urbana sufre la bestialidad de cada uno de ellos empeñados en imponer un baño de sangre público. Es el estallido del salvajismo y de la violencia de los seres habitando este espacio urbano desde el cual se proyecta una deshumanización. Así se hace evidente la intensa problemática nacional e internacional que enfrentan las sociedades humanas amedrentadas por la presencia de los Otros, como una consecuencia más de los "crecientes fenómenos de fragmentación del espacio urbano" (Guerrien 2006: 1) y de la injusta distribución social de la riqueza y de los poderes dominantes. 
El espectador no puede menos que horrorizarse por lo que observa para después reconocer aquello que se le está proyectando en La zona: las visiones del colapso de las comunidades urbanas y rurales mexicanas en el naciente siglo XXI. Esta es una situación que se extiende también a la mayoría de los centros urbanos y megalópolis; porque, "No sólo las élites se segregan cada día más, sino también otros grupos sociales medios y populares siguen un patrón similar por razones de seguridad" (Quesada 2006: 4). Esta separación urbana entre los distintos sectores sociales ha sido observada en la mayoría de las ciudades tanto del primer como del tercer mundo:

\begin{abstract}
De hecho, más allá del caso mexicano, todos los espacios urbanos donde se observan hoy fenómenos espectaculares de fragmentación tienen en común el haber experimentado durante las últimas décadas crecimientos demográficos muy importantes, esencialmente alimentados por flujos migratorios. Por ejemplo, en Estados Unidos, las ciudades donde se encuentran las más importantes concentraciones de gated communities se ubican en los estados del sur (California, Nuevo México, Texas, Florida) caracterizados por importantes migraciones procedentes de los países del sur y particularmente de América Latina. (Blakely, Snyder, 1997). [...] De este modo, el sentimiento de inseguridad socioeconómica también debe ser tenido en cuenta para explicar el repliegue de las clases superiores mexicanas en circuitos privados y el desarrollo de formas arquitectónicas cerradas y defensivas. (Citado por Guerrien 2006: 19-20)
\end{abstract}

Pero este cine tan duro sirve para ilustrar y enfrentar a los espectadores con una comunidad oscura, un mundo segregado en el que se ven atrapados los habitantes de este barrio seudo-toscano, seudo-californiano, construido al interior de la misma ciudad de México. Hay aquí un retrato/relato/imagen de una sociedad mexicana atemorizada, segregada, deshumanizada. Esta ciudad se asemeja al barrio de Santa Fe que es una ciudad buyente "sin espacios públicos, enfrentado a su entorno, que parece como una ciudad amurallada para uso exclusivo de sus residentes acomodados y acobardados" Borja 2003: 108). La pantalla se llena del horror y miedo de los moradores de La zona que al parecer pierden todo sesgo/rasgo humano ante el cerval miedo de los otros, sus desconocidos vecinos que viven al otro lado de los muros. La única luz armoniosa y brillante del espacio donde se ubica esta comunidad se ve cortada de tajo por la barrera electrificada y amurallada de esta zona residencial que divide a la comunidad pudiente y opulenta de sus vecinos que pululan por entre los barrios más pobres y miserables de la urbe:

La percepción de ambos sectores sociales del espacio urbano es de contundente presencia. Unos miran a los otros a través del muro, pero desde diferentes perspectivas; la que establece privilegio, la visibilidad ideal, es la del cerro, porque observan cual anfiteatro griego al condominio habitado por los temerosos residentes de "La Zona", quienes, a su vez, observan una colmena gris amurallada y escalonada, de intensa monotonía habitada por un número incontable de personas. (Fernández et al. 2009: 136)

La zona es sin lugar a dudas una visión paradigmática de lo que les acontece a esos pobladores que viven en las islas, fragmentos y fortificaciones de las ciudades que, como las del México proyectado, han perdido el derecho a vivir libremente a habitar su propia ciudad. Esta película es una de las más recientes y violentas historias llevadas al cine por medio de la cual se intenta concientizar/politizar a la sociedad mexicana sobre aquello que realmente está afectando y confrontando la vida de los ciudadanos: la injusticia social, la corrupción y el terror provocado por la violencia rampante. De este modo, el espectador se ve enfrentado a una realidad extrema y cruda que lo sacude, lo perturba, y que, parafraseando a Walter Benjamin (1969), le ofrece una manera de ajustarse a los amenazantes peligros que lo acechan, de enfrentar a la inseguridad, la criminalidad y al terror circundante. Del mismo modo,

El miedo al contacto con la violencia, con la pobreza, con los problemas de la vida urbana, provoca el encerramiento en espacios idealizados en los que la segmentación llevada a los extremos genera una intimidación más terrible e injustificada de la que se vive afuera. (Fernández et al. 2009: 136) 
Son peligros representados son aquellos cuyas causas de origen están en las perennes injusticias ejercidas y fomentadas por los grupos en el poder: los endémicos males sociales que como la pobreza, el racismo, la violencia no se han resuelto y ponen en riesgo la existencia de sus habitantes y de la misma casa que habitan, el mundo.

La historia central vista en La zona, en palabras de propio director Rodrigo Plá, es "la historia de un asalto a mano armada y de la cacería de un hombre, pero sobre todo es la historia de una sociedad rota, dividida, la historia de dos mundos que se temen y se odian entre sí" (Citado en LaHiguera.net). Toda violencia viola los derechos a la vida, a la libertad y al bienestar del grupo. Lo imprevisto o visualizado para la ciudad de México del porvenir, es ya parte de la realidad histórica; porque

\footnotetext{
Los habitantes de la zona, con un estatuto jurídico especial que, junto con la corrupción policial, les permite disfrazar una cacería humana y un linchamiento con el ropaje de la legítima defensa, pretenden vivir en un oasis de riqueza y felicidad en un país devorado por la violencia y la corrupción [...] Deseando ignorar este México real, los habitantes de La zona se sumergen en un México de seguridad y orden que las luminosas imágenes que abren la película -y, casi, la cierran- nos revelan como un paisaje fabricado de casas iguales, calles de trazado rectilíneo y jardines geométricos, vigilado constantemente por el ojo de las cámaras. Luz y colores, tranquilidad y control, todo se rompe por un accidente no previsto por quien vigila: la tormenta, que, recordándonos la incertidumbre que impregna el orden natural de las cosas, abre un paso en el muro, en la frontera y une los dos Mexicos, falsamente diferentes y artificialmente separados. (Gonzalvo et al. sf: 8)
}

El horror de lo que sucede en La zona intensifica el miedo a los demás y exacerba la falta de libertad en este espacio privado, inserto al interior de la urbe; mismo que se encuentra cercado/plagado por los males de la época: "la visión dominante sobre la ciudad es masculina, y su racionalidad es la del poder" (Borja 2003: 246) Esta historia es la puesta en claro de un ambiente espantoso y sombrío que puebla a las zonas urbanas enfrentadas, dos zonas o dos mundos tan diferentes en los que viven Alejandro y Miguel. Ambos protagonistas comparten un mismo mundo multicultural globalizado al que se le quiere eliminar/homogeneizar y ellos, como jóvenes que son, experimentan una fuerte curiosidad y rebeldía ante esto. A la vez, ambos comparten una misma experiencia dentro de estos mundos hostiles que los separan y un destino diferente que los unirá; por eso, hacia el final, unen esfuerzos por salir/sobrevivir/dejar una existencia llena de cicatrices y recuerdos oscuros en donde no hay espacio para el que es diferente, para el que piensa del por qué viven detrás de un muro. Ahí, a cualquiera le puede ocurrir un accidente, una alteración o una catástrofe al correr el riesgo de ser mal entendido o eliminado tal y como le acontece a Miguel y a sus cómplices.

La barbarie cometida por la gente de La zona va a parar no sólo al cementerio, sino también a "la otra ciudad" donde cada uno de sus habitantes detenta, haciendo eco a lo dicho por Michel Foucault, una negra morada... Son estas palabras e imágenes al interpretar el desenlace final de la película, las mismas que encuentran un eco en las versificaciones proféticas hechas por José Emilio Pacheco quien en su Miro la tierra, su sección III La tierra desconoce la piedad, parte V nos dice lo está viendo, lo que sucedió en Ciudad de México:

\footnotetext{
El lugar de lo que fue la casa lo1 ocupa ahora

un hoyo negro (y representa el país entero).

Al fondo de este precario abismo yacen pudriéndose

escombros y basura y algo brillante.

Me acerco a ver qué arde amargamente en la noche

y descubro mi propia calavera.
} 
La huída de Alejandro hacia las calles de la gran ciudad hacen más visibles esas vivencias deshumanizadoras y altamente homogenizadoras dentro de una zona que intentaba ser una casa-mundo para sus moradores y que, sin embargo,resulta ser un seudo espacio familiar lleno de una modernización globalizadora segregante que acaba en el desastre. Compartimos esa misma visión infausta y al comprenderla más, al profundizar en lo visto en la pantalla, se perfilan nuestras sombras "qué arde(n) amargamente en la noche”. Ese mismo destino trágico sufrido por los tres jóvenes ladrones que incursionaron en La zona, lo compartimos también nosotros, porque es parte del caos que se avizora para los habitantes de todas las megalópolis, que como la ciudad de México, inmola a sus jóvenes. Tal es el destino de Alejandro, quien al desilusionarse de sus padres, de sus amigos y vecinos, abandona su falso hogary se pierde entre las calles, entre el mar urbano y entre las negras sombras desplegadas por la violencia deshumanizadora que trágicamente cubren su camino. La zona, engolfada por la ciudad monstruosamente insensible, proyecta una violencia oscurecida con la que se señala esa intensa problemática que no es sólo local sino quetambién es mundial. Así, yo también Miro la tierra...

\section{Bibliografía}

Álvarez, Ana et al. 2007. Citámbulos: el transcurrir de lo insólito: guía de asombros de la ciudad de México. Mexico: Conaculta.

Benjamin, Walter. 1969. "The Work of Art in the Age of Mechanical Reproduction". Illuminations. New York: Schocken.

Bittarello, Beatrice. 2008. "Another Time, Another Space: Virtual Worlds, Myths and Imagination". Journal of Virtual Worlds Research. 1 (1): 1-18. http://journals.tdl.org/ jvwr/article/view/282

Bonastra, Quim; Fraile, Pedro; Arella, Celeste y Gabriela Rodríguez (Eds.). 2006. Paisaje ciudadano, delito y percepción de la inseguridad investigación interdisciplinaria del medio urbano. Madrid: Editorial Dykinson.

Borja, Jordi. 2003. La ciudad conquistada. Madrid: Alianza Editorial.

Castellanos, Laura. Entrevista realizada el 1 de enero de 2008. Entrevistador: Mario Casasús. http://www.rebelion.org/noticia.php?id=61012

Chambers, Iain. 1994. Migrancy, Culture, Identity. London and New York: Routledge.

Davis, Mike. 2006. Planet of Slums. London-New York: Verso.

Fernández, Gerardo; Martí, Sandra y Martha Isabel Flores. 2009. "La zona: La idea de protección a partir del libre confinamiento en la sociedad globalizada". Nueva época. 22 (61): 127- 138. http://es.movies.yahoo.com/l/la-zona/critica-3550720.html 
Foucault, Michel. 1984. "De los espacios otros: Des espaces autres”. Conferencia dictada en el Cercle des etudes architecturals 14 de marzo de 1967. (Trad. Blitstein y Lima). Architecture Mouvement Continuite. http://www.scribd.com/doc/4650039/FoucaultM-De-los-espacios-otros

García Alvarado, Rodrigo. sf. “QQué están dando en el cine? Cinematografía y arquitectura: cronología de un desencuentro". Arqchile.cl. http://www.arqchile.cl/cine_arquitectura.htm

García Canclini, Néstor. 1999. La globalización imaginada. México: Paidós.

2003. "México 2010: una ciudad que improvisa su globalización”. Alteridades. 13 (26): 7-14.

Gelman, Juan. 2008a. Gotán. Buenos Aires: Booket.

2008b. Mundar. México: Era.

Gonzalvo, Angel et al. sf. Guía didáctica: “Un día de cine Ies Pirámide Huesca”. http://www. undiadecineiespiramidehuesca.com

Guerrien, Marc. 2006. “Arquitectura de la inseguridad, percepción del crimen y fragmentación del espacio urbano en la zona metropolitana del Valle de México". En: Bonastra et al., 93-116.

Krieger, Peter. 2007. "Citambulantaje: Percibir, comprender y aprovechar los imaginarios de la Megaciudad de México”. En: Álvarez et al., 347-359.

Langagne, Eduardo. 2004-2005. "Memoria y ciudad". Cultura urbana. (diciembre 2004- enero 2005): 43-46.

León-Portilla, Miguel. 2004. "La construcción de significado en la historia". El concepto de realidad. Verdad y mitos en la ciencia, la filosofía, el arte y la historia. México: El Colegio Nacional.

Lina, Pedro. 2005. "Las puertas de la "microciudad" de México y la ecología del miedo". Scripta Nova Revista Electrónica de Geografía y Ciencias sociales. 9 (194): 55. http:// www.ub.edu/geocrit/sn/sn-194-55.htm

Lindón, Alicia. "La ciudad y la vida urbana a través de los imaginarios urbanos". EURE. 33 (99): 7- 16.

2007. "Diálogo con Néstor García Canclini. ¿Qué son los imaginarios y cómo actúan en la ciudad?". EURE. 33 (99): 89-99. 
Makowski, Sara. 2007. “Ciudad de México: territorios de la exclusión”. Espaço Plural. 8 (17): 9-16. http://132.248.9.1:8991/hevila/Espacoplural/2007/vol8/no17/1.pdf

Pacheco, José Emilio. 1995. Miro la tierra. México: Era.

Pasantes, Herminia. 1999. "El amor está en el cerebro no en el corazón”. Testigos de nuestro tiempo: diálogos con personajes de hoy. Entrevista realizada por Ana Cruz. México, D.F.: Canal 22, Televisión Metropolitana. México: Fondo de Cultura Económica.

Plá, Rodrigo. 2007. La zona. México: Morena Films y Buenaventura Producciones, color, 93 min.

sf. La zona. Notas del director. LaHiguera.net. http:/www.lahiguera.net/cinemania/ pelicula/3004/comentario.php

Quesada, Florencia. 2006. “Imaginarios urbanos, espacio público y ciudad en América Latina”. Pensar Iberoamérica. 8: 1-9. http://www.oei.es/pensariberoamerica/ric08a03.htm

Sontag, Susan. 2003. Ante el dolor de los demás. Argentina: Alfaguara. 
